\title{
Editorial
}

\section{Lipid Lowering Treatment: Current Issues}

\section{A R M Saifuddin Ekram'}

Lipid lowering treatment is of benefit in the prevention of coronary heart diseases. (CHD) and other vascular events. ${ }^{1}$ So far many siudies have been cartied out to prove the safety, efficacy and beneficial effects of lipid-lowering treatment in varions countries. These studies can be categorized into two groups: (1) studies done to prove the effectiveness of lipid lowering treatment in the primary prevention of coronary heart diseases e g. WOSCOPS or West of Scotland Cororiary Prevention Study (1995) and AFCAPS/ TEXCAPS or Airforce/Texas Coronary Atheroselerosis Prevention Study $(1995)^{2}$ (2) studies done to prove the effectiveness of these drugs in the secondary preyention of coronary heart disease e.g. CARE or Cholesterol And Recurrent Events trial (1996) and LIPID or the Long-term Intervention With Pravastatin in Ischaemic Heart Disease $(1998)^{3}$.

The results of the studies done for primary prevention of CHD with lipid lowering dngss are confirmatory and re-assuring. They also included women; though their number were relatively lower but it is proved that women are benefited from lipid lowering treatment in prevention of $\mathrm{CHD}$ as well. Benefit was apparent across all baseline levels of cholesterol and it was greatest in those at greatest risk e.g. in those with concomitant hypertension or diabetes mellitus. ${ }^{2}$

The trials done for secondary prevention of coronary heart diseases ICARE (1996) and LIPID (1998)1 3,4 revealed that in patients with CHD and a broad range of cholesterol levels, cholesterol lowering therapy reduces the risk of coronary events but the effects on mortality from $\mathrm{CHD}$ and overall mortality have remained uncertain. However, there was a reassuring consistency in the findings of lipid relative to the results of $4 S^{5}$ and $\mathrm{CARE}^{4}$, which led the authors to conclude that cholesterol-lowering therapy should now be considered for virtually all patients presenting with CHD. So now it can be said that the recent clinical outcome irials have placed the "final seal of approval" on lipid-lowering treatment in patients known to have $\mathrm{CHD}^{3}$.

But there are some unresolved questions: (1) What is the optimal target concentration for total and/ot LDL cholesterol? (2) How important are the concentrations of $\mathrm{HDL}$ cholesterol and triglycerides? (3) Which drugs are ultimately cost-effective? (4) There is a discrepancy between "recommendation" and "implementation". How shall we fill up this gap?

EUROASPIRE survey ${ }^{6}$ demonstrated u high prevalence of modifiable risk factors among the patients of $\mathrm{CHD}$ e.g. uncontrolled hypertension, lipid abnormality, poorly controlled diabetes mellitus, etc: But effective management of hypertension and dyslipidaemia (together with hyperglycaemia) is well justified by current scientific evidence and there would be clear benefits in terms of reduced needs for revascularization procedures, fewer hospitalizations and lower CHD morbidities and mortality. That is why the EUROASPRE study concluded that there is a considerable potential for physicians and cardiologists to reduce CHD further in addition to morbidity and mortality and improve chances of patient survival.

Now there are people who advocate dietary modifications as an important way of lowering cholesterol. But how far these dietary modifications can be helpful? Dietary intervention trials to fower blood total cholesterol in free living subjects with average motivation have proved that it is of modest effectiveness. This can reduce total cholesterol at best $5-10 \%$ of existing level?. Various studies have shown that despite good compliance, very low fat diet alone does not achieve recommended cholesterol gosls in outpatients with coronary heart disease.

' Associate Prolessor, Deparment of Mecicine, Rajshahi Medical College, Rajshahi-6000, Bangladesh. 
A clinically diagnosed case of dengue was defined as a person with fever and 2 or more of the following symptoms: headache, retro-orbital pain, myalgia, arthralgia, rash or haemorrhagic manifestations in the form of petechiae and positive tourniquet test in the early stage. ${ }^{13}$ In DHF there may be haemorrhage in the form of bleeding from mucosa mostly epistaxis or gum bleeding and bleeding from injection or other sites. Haematemesis, melaena, haematuria and menorrhagia also occur. This study was done to observe the clinical presentation of various form of dengue syndrome.

\section{Patients and Methods}

This is a descriptive study and was carried out at Khuina Medical College Hospital with three hundred and sixty eight patients admitted to dengue ward from August 2000 to Dec, 2000. All the patients irrespective of age and sex were included in the study. After admission detailed history of the patients was taken and thorough examine and the clinical presentations were noted in detail.

The diagnosis of dengue fever (DF), dengue haemorrhagic fever (DHF) and DSS (Dengue shack syndrome) was made on clinical basis mainly. Tourniquet test was done in all the cases. Haematocrit estimation and platelet count was done in all the cases but serological test could be done in limited number of patients because of lack of facility in the hospital.

The patients were kept under close supervision during the period of hospital stay and its outcome was noted.

\section{Results}

368 cases of DF. DHF and DSS cases of both sexes male $240(65.21 \%)$ and female 128 $(34.78 \%)$ was studied. The age of the patients ranged from 1-70 yrs. But the majority of patients $309(83.96 \%)$ was between $1-30$ years (Table-I).
Clinical presentations of the patients were noted. Fever was the presenting feature in all the patients $(100 \%)$. Headache was in 115 (31.35\%), rash in $105(28.53 \%)$ and body ache in $98(26.63 \%)$ cases. (Table-II)

The common haemorrhagic manifestation was haematemesis and melaena in $206(55.97 \%)$ cases and others were epistaxis, gum bleeding and conjunctival haemorrhage. (Table-III). Tourniquet test was done in all the cases but it was found positive in 215 (58\%) patients. Haematocrit was increased in most of the cases and was normal in few cases. Platelet count was also variable. (TableIVA \& IVB),

The patients included in the study were diagnosed as DF, DHF \& DSS (Table-V).

During the course of treatiment the outcome was noted. Majority of patients ( $94.56 \%$ ) recovered well. (Table-VI).

Table-I:

\begin{tabular}{lll}
\hline Age in years & No. of patients & Percentuge ( $\mathrm{g})$ \\
\hline $0-10$ & 81 & 22.01 \\
$11-20$ & 134 & 36.4 \\
$21-30$ & 94 & 25.54 \\
$31-40$ & 30 & 8.15 \\
$41-50$ & 17 & 4.61 \\
$51-60$ & 08 & 2.17 \\
$61-$ above & 04 & 1.08 \\
\hline
\end{tabular}

Table-II:

\begin{tabular}{lcc}
\hline $\begin{array}{l}\text { Clinical } \\
\text { presentation }\end{array}$ & No. of patients & Percentage (\%) \\
\hline Fever & 368 & 100 \\
Heudache & 115 & 31.25 \\
Rash & 105 & 28.53 \\
Body ache & 98 & 26.63 \\
Vomiting & 88 & 23.91 \\
Abdominal pain & 60 & 17.93 \\
Retro-orbital & 45 & 12.22 \\
pain & & \\
Loose motion & 09 & 2.94 \\
Joint pain & 03 & 0.8 \\
\hline
\end{tabular}


Table-III:

\begin{tabular}{lcc}
\hline $\begin{array}{l}\text { Haemorrhagic } \\
\text { manifestation }\end{array}$ & $\begin{array}{c}\text { No. of } \\
\text { patient }\end{array}$ & $\begin{array}{c}\text { Percentage } \\
(5 \%)\end{array}$ \\
\hline Hacmatemesis and melacna & 206 & 55,97 \\
Gum bleeding & 61 & 16.57 \\
Conjunctival haemorrhage & 40 & 10,86 \\
Epistaxis & 23 & 6.25 \\
Hacmaturia & 16 & 4.34 \\
Huemoptysis & 12 & 3.26 \\
Menorthagia & 05 & 1.35 \\
\hline
\end{tabular}

Table-IVA: Platelet count of the patients

\begin{tabular}{lcc}
\hline Platelet count & No, of patients & $\begin{array}{c}\text { Percentage of } \\
\text { putients (5) }\end{array}$ \\
\hline$<50,000 / \mathrm{cmm}$ & 24 & 6.52 \\
$50,000-100,000$ & 56 & 15.21 \\
$100,000-150,000$ & 32 & 8.69 \\
$150,000-200,000$ & 174 & 47.28 \\
$>2(00,000 / \mathrm{cmm}$ & 82 & 22.28 \\
\hline
\end{tabular}

Table-IVB: Hatematocrit of patients

\begin{tabular}{lcc}
\hline Haematocrit & No. of patients & $\begin{array}{c}\text { Percentage } \\
\text { of patients } \\
(\%)\end{array}$ \\
\hline $45 \%$ & 77 & 20.92 \\
$54 \%$ & 155 & 42.11 \\
$56.25 \%$ & 88 & 23.91 \\
$58.5 \%$ & 48 & 13.04 \\
\hline
\end{tabular}

Table-V

\begin{tabular}{lcc}
\hline Diagnosis & No. of patients & $\begin{array}{c}\text { Percentage } \\
(\%)\end{array}$ \\
\hline DF & 167 & 45.38 \\
DHF & 185 & 50.27 \\
DSS & 16 & 4.34 \\
\hline
\end{tabular}

Table-VI

\begin{tabular}{lcc}
\hline Outcome of treatment & $\begin{array}{c}\text { No, of } \\
\text { patients }\end{array}$ & Percentage \\
\hline Improved and dischurged & 348 & $94.56 \%$ \\
Expired & 15 & $4.07 \%$ \\
Referred to higher center & 0.5 & $1.35 \%$ \\
\hline
\end{tabular}

\section{Discussion}

Though sporadic cases of DF and DHF were reported in our country during the last few years, it has emerged as an epidemic since July 2000. A lot of controversy exist regarding whether dengue is an emerging, reemerging or imported discase in our country., 11 Dengue syndrome was detected for the first time in this country in 1964 which was remarkably known as 'Dhaka fever'. ${ }^{14}$ Subsequently dengue was detected in a survey in Chittagong in 1996 through 1997 and later in 1998 and 1999, cases of dengue fever was reported in the media in Dhaka city. ${ }^{5}$ So we can say that dengue was sporadic in this country which bas emerged as an epidemic during post monsoon period of 2000. It may not be out of place to mention that dengue might be imported from neighbouring countries by the modern transportation system like direct bus/train communication and especially air craft.

In Thailand a retrospective study showed that DHF was commonly found in patients whose age ranged from 10-14 years. ${ }^{15}$ In our study, the result is similar that is majority of our patients are below 20 years $(58.42 \%)$ and below 30 years was 309 $(83.96 \%)$. This is also identical with other studies. $^{12,13}$

Studies in other countries revealed that $90 \%$ of hospitalized dengue patients are children less than 15 years of age, ${ }^{12}$ Disease trend of DF and DHF in many countries reveal that initially it affects people of all ages bat gradually children become the most susceptible group. ${ }^{12}$ It might be because children are more vulnerable to mosquito bite.

Among the clinical presentations the common were fever $(100 \%)$, headache $(31.25 \%)$, rash (28.53\%), body ache $(26.63 \%)$ which fit WHO criteria for diagnosis of dengue fever. ${ }^{12}$ Among the haemorrhagic manifestations in DHF, the commonest was haematemesis and melaena $(55,97 \%)$, Others were gum bleeding, conjunctival haemorrhage and epistaxis which was revealed in other studies also ${ }^{13}$ Menorrhagia was present in $05(1.35 \%)$ cases, which was also found in other studies, $^{16}$ Haematocrit of the patierns was estimated and in most of the cases was increased. 
Plafelet count was also done and the count was low in most of the cases which is helpful in diagnosis of dengue fever. ${ }^{4,6}$

Incidence of DHF is increasing in countries of South East Asian region. ${ }^{12}$ In our study we got cases of DHF $185(50.27 \%)$. Mortality from DHF and DSS averages $5 \%$. ${ }^{12}$ In our study mortality from DHF/DSS are only $4.07 \%$, which is comparable with other Asian countries.

Few patients, $5(1.35 \%)$ were referred to Dhaka for concomitant diseases like ARF and requiring platelet concentrate transfusion, which is not available here.

In absence of specific therapy and vaccination, the only way of saying our people is the prevention of spread of the disease by eradicating the mosquitoes and eliminating breeding sites in and around our houses, specially in towns and cities. Creation of awareness by mass media like Radio. Television and Newspapers can help in this respect. Different government and nongovernment organization (NGOs) can undertake appropriate measures for this purpose.

\section{Acknowledgement}

We gratefully acknowledge the hard labour and sincerity offered by Dr. Chandra Shekhar Bala, Internee doctor who engaged himself for collecting the data of large number of patients.

\section{References}

1. Fruttaldo $L$, Schettino $G$, Mongio $F$, Gatti $G$, Deambrogio V. A case of dengue from Puna, India. J Travel Med 2000; 7(1) 46-7.

2. Istuviz RE, Gubler DJ, Brea Del Castillo J. Dengue and dengue haemorrhagic fever in Latin America and the Caribbean. Infec Dis Clin North Am 2000: 14(1): 121-40

3. Chaturvedi UC, Agarwal $R$, Elbishbishi EA, Mustafa As. Cytokine cascade in dengue haemorthagic fever: Implication for Pathogenesis. Immunol Med Microbiol 2000: 28(3): 183-8.
4. Srichaikul T, Nimmannitya S. Haematology in dengue and dengue haemorrhagic tever. In: Baillieres Best Pract Res Clin Haematol 2000: $13(2): 261 \cdot 76$.

5. Yunus EB. Dengue outbreak 2000; The Emerging issues. Bang Med $\mathrm{J}$ (Khui) 2000; 33: 46-47.

6. Alam MN. Dengue and Dengue haemorrhagic fever in Bangladesh. The Orion (Medical bulletin) 2000; 6: 7-10.

7. Cavey DE. Chikungunya. Dengue a case of mistaken identity. I Hist Med 1971; 26: 243-62.

8. Thaung U. Dengue haemormagic fever in Burma Asian J int Dis 1978; 2:23.

9. Yunus EB. Dengue and Dengue haemorrhagic fever: Bangladesh Perspective. JCMCTA 1999; 10: $1-8$

10. Yunus EB, Banu Dilrose, Talukder KA, Chowdhury MJQ. Bangali AM. Report on Sero epidemiological study of dengue and dengue haemorrhagic fever ICOVEO Project, Directorate General of Health Services, 1998.

11. HAMN Ansan, $\mathrm{CH}$ Rasul, SR Karim, AA Mamun, MA Bakar, EA Gazi. Dengue an epidemiological study, Bang Med J (Khul) 2000; 33: 48-50.

12. Lyeria R, Rigaha Perez JG. Vomdam AV, Reiter P. George AM, Potter IM, Gubler DJ. A dengue outbreak among camp participants in a Canibbean island, 1995, J Travel Med 2000; 7(2): 59-63.

13. Dengue and Dengue haemorrhagic fever. In WHO. Prevention and control of Dengue and dengue haemorrhagic lever WHO/SEARO Publication no. 9, New Delhi, 1999; 3-9.

14. Aziz MA, Gorlan JA, Gregy MB, "Dacca Fever" an outbreak of dengue fever. Pak $J$ Med Re 1967;6: 83-9.

15. Chuansumnit A, Phimothares V, Tardfong $P$, Tapaneya-Olarn, et al. Transfusion requirement in patients with dengue haemorrhagic fever, South Asian J Jrop Med Public Heallh 2000; 31(1): $10-4$

16. McGready $A$, Paw $E_{i}$ Nosien $F$. Menormagia caused by dengue fever. Aust $\mathrm{Nz} J$ Obstet Gynaecol 2000; 40(3): 354-5.

All correspondence to: Dr. Md. Abu Bakar

Associale Protessor

Department of Medicine Khuina Medical College, Khulna, Bangladesh 